\title{
Jordanian EFL Teachers' Attitudes towards Dictionaries and their Use in EFL Classrooms
}

\author{
Mahmoud Mamdouh Baker Omar M. Bani Mofarrej Nassar Mohammad Al-Shatnaw \\ School of Laguages, University of Jordan, Queen Rania Street, Amman, Jordan
}

\begin{abstract}
The present study is an attempt to investigate EFL university teachers' attitudes about the importance of the dictionary as an effective learning tool. It also aims at identifying the type of dictionaries preferred by teachers and the types of skills that EFL learners can be improved by the use of the dictionary. Forty EFL teachers responded to a written questionnaire, which included 22 statements. The findings generally revealed that participants do have positive attitudes towards the dictionary as a learning aid. Moreover, the findings revealed that electronic dictionaries are preferred over paper-based ones. However, contrary to our expectations, the findings revealed that although EFL university teachers appreciate the importance of the dictionary, they do not pass this positivity to their students and that they believe using a dictionary is the students' responsibility. The study concluded that by incorporating dictionary usage into classroom practice regularly, EFL teachers will raise their students' awareness of the type of information they can find in the dictionary, how they can use it to serve academic purposes, and become more autonomous learners.
\end{abstract}

Keywords: Communication, dictionary, EFL teachers, pedagogy.

DOI: $10.7176 / \mathrm{JEP} / 11-26-07$

Publication date:September $30^{\text {th }} 2020$

\section{Introduction: Preliminary Remarks}

Over the past few decades, the technological revolution was accompanied by a growing interest in intercultural communication. Consequently, the world is becoming more internationalized, which suggests that there is a crucial need for tools that help intercultural communicators, as well as language learners, better understand one another. The dictionary is one of the most important tools that facilitate and support the process of learning and communication. In the last few decades, a great deal of ink has been spilled on dictionary designs as well as dictionary consultation habits. This is largely attributed to the importance of dictionaries in extending one's knowledge of their language or that of a second/foreign language. In this respect, Ilson (1985) maintained that "the dictionary is the most successful and significant book about language" (p. 1).

Dictionaries have a long-debated history in their forms, organizations, items to include, among many other controversial issues. In its general sense, a dictionary can be treated as a reference book that includes alphabetically listed words along with their meanings, pronunciations, and illustrative examples. It is considered a reference for users' needs simply because "Language learners need language learning resources, including dictionaries" (Adamska-Salaciak and Kernerman, 2016, p.272). However, one should note that dictionaries are not produced to describe languages, rather they give information that is used to solve learning problems.

As technology develops, it revolutionizes cultural, social as well as linguistic means. Before this technological revolution, dictionaries had only appeared in printed forms, which poses some kind of difficulty to dictionary users. Along with these lines, Nesi (1999) claimed that "it is inevitable that the more information the paper-based dictionary contains, the harder (and more time-consuming) it will become for learner users to find exactly what they need to know" (pp. 56-7) [emphasis original]. However, in recent years, more and more electronic forms of dictionaries have been available for all kinds of users, which is claimed to have many benefits over the use of paper-based dictionaries. Electronic dictionaries make the consultation process easier, faster, and more convenient for language learners or dictionary users who may consult a dictionary for a variety of reasons.

In this connection, Chun (2004) pointed out that "online and CD dictionaries provide user-friendly functions in searching and provide quick access to entry information". From a simple point of view, users usually consult a dictionary to look up the meaning of a certain word, check the spelling as well as to look for pronunciation. At a more advanced level, users may visit a dictionary to find synonyms, collocations, and contexts in which to use certain words, just to mention a few. It is claimed that a dictionary is one of the very few resources that can give us the best and most comprehensive information about words. This goes in line with the general conviction that the information provided in a dictionary is accurate, authentic, and reliable.

The researchers founded their argument, here, based on the general assumption that if the EFL teachers are highly interested in dictionary use and are aware of the importance of dictionaries, and lexicography in general, they will certainly pass this interest to their students. In this respect, Hartmann (1983) reported that "the foreign language learner needs a new interlingual dictionary to meet his particular needs" (p. 199). The present study, therefore, concerns itself to shed light on the Jordanian university EFL teachers' attitudes towards dictionaries in general and the use of electronic dictionaries in particular. The study aims at answering the following two questions: 
1. What are English university teachers' attitudes towards dictionaries?

2. To what extent do they encourage their students to use dictionaries inside or outside the classrooms?

\section{Limitations of the Study}

This study is general. The sample of the present study is relatively small, with only 40 EFL teachers. Therefore, the sample of future research may include a larger sample. It is also restricted to three Jordanian universities, two public, and one private university. Future research may include more universities at the national level.

\section{Review of related Literature}

The study of dictionary use and consultation habits flourished in the last few decades. Many researchers have attempted to prove the importance of dictionaries in the process of language learning and language teaching process. In this connection, Trap (2004) pointed out that "Dictionaries can be conceived to assist the learner in different aspects of the language-learning process" (p. 222). During the last few decades, a large number of researchers attempted to provide insights into different aspects of dictionary use and consultation habits. Technological advances make it possible for dictionary designers to develop and innovate new forms of electronic dictionaries that meet the users' needs of a tool for communicative as well as educational purposes, and to facilitate the process of searching information by providing learners with a user-friendly type of a dictionary.

One of the most important studies is that of Nesi (1999) who described the effects of computer technology on the design and use of a range of dictionaries for language learners, from pocket bilingual dictionaries contained within a tiny electronic device to multi-media interactive monolingual dictionaries on CD-ROM. She maintains that the new way of search available to electronic dictionary users is of great usefulness and success. Besides, she also provides some pedagogical and educational potential of computer-based dictionaries in the language classroom. In the last section of her paper, Nesi (1999) provided some advice for teachers who are interested in using such electronic dictionaries. For instance, she stated that "A dictionary that can only be accessed via a desktop computer is not suitable for receptive purposes such as reading print and listening to lectures" (p. 64). Also, "The pedagogical potential of electronic dictionaries is too great to be ignored, even by institutions with few resources. A single CD-ROM on a single computer can provide a huge amount of classroom material" (p. 65).

Recently, due to the huge improvement of technological devices, more and more types of dictionaries have been available for all types of users. You can hardly find a Smartphone user who has no access to a certain type of dictionary. Even if one asks cell-phones holders a simple question like: Do you have a dictionary uploaded on your phone? The answer will be YES, even though they may not use it constantly. However, they, maybe unconsciously, uploaded such a tool because they feel safe and since they are aware of the fact that dictionaries are an indispensable part of the learning and communication process.

Further, Nesi (2002) investigated the dictionary consultation habits by some international students at a British university. Six groups of international students were assigned to report, over three years, on how they used dictionaries while looking up the meaning of unknown words. Eighty-nine reports were analyzed. The results revealed that almost half of the participants were unsuccessful in finding the meaning of at least one consultation. The difficulty was that participants failed to find the appropriate entry and some sub-entries in the dictionaries. The study concluded that the participants were unaware of the serious misinterpretation that resulted out of such use of the inappropriate entries selected.

Within the same line, Dziemianko (2010) conducted a study to compare the effectiveness of a monolingual English learners' dictionary, COBUILD6 (2008), in paper and electronic forms in receptive and productive tasks. The study further tried to assess the role of the type of dictionary in the retention of meaning and collocation. The results revealed that the electronic version of COBUILD was more useful in both, receptive and productive, tasks. Concerning the retention test, the findings showed that the electronic dictionary was a better learning tool that significantly enhanced the retention of the meaning as well as the collocation.

Due to the lack of studies on the teachers' and students' attitudes towards electronic dictionaries in the Iranian culture, Dashtestani (2013) conducted a study to compare the Iranian EFL students' and teachers' attitudes towards the use of electronic dictionaries. The participants were 126 EFL students and 73 EFL teachers. The data obtained through the use of questionnaires. However, at a later stage, eighty-one students and 66 teachers took part in follow-up interviews. The findings revealed that both teachers and students had relatively positive attitudes towards using electronic dictionaries for learning EFL. However, participants indicated that some many difficulties and challenges face EFL learners. They reported that one of the most important obstacles is that EFL learners do not receive any training on the use of such electronic dictionaries. Moreover, participants claimed that EFL classrooms lack facilities to help them use these dictionaries. The findings also revealed that Iranian EFL students preference for using electronic dictionaries that they installed on their smartphones. However, they reported that they just needed more training on how to choose an appropriate electronic dictionary.

Recently, much effort has been paid to investigate the effectiveness of bilingual dictionaries on the overall achievements of EFL learners in various languages. For example, Lew (2016) investigated the effectiveness of a bilingual dictionary for Polish learners of English, namely: Longman Slownik Wspo'lczesny by Fisiak et al. (2004), 
on the writing process of Polish EFL learners. The sample consisted of three groups of Polish final-year secondary school students; in the first group, participants had access to a paper-based copy of the dictionary, the second group were able to use an electronic copy of the dictionary whereas the third group - the control - had no access to any type of the bilingual dictionary. The findings revealed that the first two groups, those who had access to either version of the bilingual dictionary, performed significantly better than the third group, the control group without access to the dictionary. The students benefited much more in vocabulary use and structure more than other areas like content and accuracy. The study concluded that the dictionary is an effective writing tool for Polish EFL learners.

In an empirical study, Liang and $\mathrm{Xu}$ (2016) explored the impact of using a dictionary when acquiring the middle construction in L 2 by Chinese students. To harvest the required data for the study, the researchers asked 86 participants to take a pre-test of the target constructions. This pre-rest revealed that the participants have very limited knowledge about this kind of construction. Therefore, a month later, the researchers asked 75 participants, divided into three groups, to translate a Chinese text, which contained four middle construction sentences, into English with the support of an experimental dictionary. The results revealed that using the dictionary and the frequent dictionary consultation habits effectively improve and facilitate the production of the English middle constructions.

In a more recent study, Kim (2017) conducted a study that described the Korean college students' dictionary consultation habits in self-editing collocation errors. Kim collected his data from four participants before and after giving them four-step instructions which targeted their collocation dictionary skills. The findings of the data that were obtained before the given instructions showed that EFL participants used entries from L1 when they looked for example sentences in the bilingual dictionary. The participants' reliance on logical reasoning or using synonyms to fix the lexical errors they encountered made collocational error correction inconsistent. However, after the participants received the instructions, they reported progress in improving the rate of their collocation correction. The study concluded that collocational dictionaries are needed and of great importance at schools as they improve the learners' collocational competence.

Some researchers even attempted to identify the best dictionary types that may have an impact on improving the learners' performance in foreign languages. For example, Metruk (2017) investigated the types of dictionaries and how Slovak EFL learners benefit from electronic dictionaries to improve their pronunciation practices. A questionnaire containing pronunciation-based questions related to the use of electronic dictionaries was distributed to 24 Slovak EFL university students. The findings revealed that the participants tended to use the electronic dictionaries quite often and that they preferred the use of monolingual electronic learner's dictionaries more than special-purpose dictionaries.

Lexicography has received much less attention from researchers in the Arab world, though Arab researchers have started to pay some attention to dictionaries and dictionary consultation habits. In an attempt to provide a better understanding of the English - Arabic bilingual dictionaries to help lexicographers develop better dictionaries for the eagerly awaited users. Benzehra (2012) maintained that lexicographers should develop guidelines and a user-friendly methodology that provides users with equivalence relations between Arabic and English lexical units. Some attempt has been made in the Arab world to examine the learners as well as the teachers' attitudes towards the importance of dictionaries.

Diab and Hamdan (1999) investigated how Jordanian EFL university students interacted with words and dictionaries while they were reading a specialized text in linguistics. The findings revealed that most participants looked up general words' meanings and pronunciations. The results also revealed that participants tended to use monolingual general dictionaries more frequently than bilingual ones. It was noted that both the printed dictionaries as well as the electronic ones were consulted. However, the use of electronic dictionaries was limited to a few EFL participants.

Al-Ajmi (2008) conducted a study in which he shed light on the effectiveness and usefulness of the dictionary examples in the word meaning comprehension. Two groups of Kuwait EFL university students participated in the study. The first group was supposed to translate ten English headwords in Arabic with the assistance of dictionary entries with examples extracted from the Oxford Advanced Learner's Dictionary (OALD) while the second group was supposed to translate without any access to dictionary entries or illustrative examples. The results revealed that the presence of dictionary examples negatively affected the students' performance; i.e. "the provision of examples along with definitions negatively affects students' ability to understand unfamiliar English words" (ibid, p. 22). This could be attributed to the claims raised by Tarp and Gouws (2012) who maintained that dictionaries may not help users solve certain problems because of "the lack of dictionary using skills" (p. 334).

Hamouda (2013) conducted a study in which he aimed at identifying the types of dictionaries used by Saudi EFL learners, the frequency of dictionary use, as well as the type of lexical information examined while consulting a dictionary. To achieve the goals of his study, he used two data-collection instruments, namely a questionnaires and interviews. Responses to the questionnaires revealed that Saudi students did not benefit from the various dictionaries available, which could be attributed to the fact they are not well trained on the best ways to use a 
dictionary. Most consultation processes were oriented to the meaning or definition of words, neglecting other aspects like collocations, word formation, and some pragmatic knowledge. The findings further revealed that electronic dictionaries were much preferable by participants than another form of dictionary and that they prefer bilingual dictionaries over monolingual ones.

In a very similar study to ours, El-Sayed and Siddiek (2014) investigated the Sudanese EFL teachers' attitudes towards the use of dictionaries as an important teaching tool. Further, they investigated the actual use of dictionaries by these EFL university teachers. A questionnaire was developed and distributed to fifty Sudanese EFL teachers who participated in the study. The findings revealed that dictionaries were not positively viewed by the teachers; instead, they believe that the use of dictionaries is the students' responsibility and not an integral part of the English program.

In a more comprehensive study, Alhaisoni (2016) explored the EFL teachers', both native and non-native, and students' perception of dictionary consultation habits. The data was obtained through a questionnaire and followed by a follow-up interview method. A total number of 99 EFL teachers, native and non-native, as well as 3993 male and female EFL students, responded to the questionnaire. On the one hand, the findings showed that students preferred bilingual dictionaries to check the meaning and spelling. The students also reported using online and electronic dictionaries more than paper-based ones. On the other hand, the results revealed that EFL teachers perceived the dictionary as having a significant role in the teaching-learning process. The study concluded that EFL teachers should pass their positive attitudes, towards dictionaries, to their students to improve the students' learning skills. This could be achieved through extensive training programs.

Further, Al-Homoud (2017) investigated the female Saudi EFL university students' use of dictionaries at their preparatory programs. Mainly, the study aims at identifying the types of dictionaries, language skills, and types of information as well as the reasons for using the dictionary. The results revealed that female participants preferred electronics over paper-based dictionaries. Further, the results revealed that participants consult their dictionaries mainly for looking up the meaning of new words or confirm the meaning they already know. The need to check for spelling and pronunciation was also found.

\section{Methodology}

The main objective of the present study is to figure out the EFL teachers' attitudes, rather than the EFL students, towards the importance of dictionaries and their consultation habits. This is based on the researchers' assumption that if teachers have positive attitudes towards dictionaries, they will certainly pass eagerness and passion about dictionaries to their students. This section presents the methods employed in the paper to accomplish the researchers' intended objectives; data collecting instrument and procedures as well as the participants of the study.

\subsection{Participants of the study}

Participants of the present study are all EFL teachers at three Jordanian universities, namely: Yarmouk University, The Jordan University of Science and Technology, and Al-Zaytoonah Private University. The sample consists of 40 EFL teachers, either MA or Ph.D. degree holders, both males, and females. However, gender is not taken as an independent variable since the number of male EFL teachers who responded to the questionnaire outweigh the number of females.

\subsection{Instrument and Procedure}

The data for the present study was mainly obtained through the use of a modified version of El-Sayed and Siddiek's (2014) questionnaire. The questionnaire consisted of 22 statements to investigate (a) the teachers' general attitudes towards the dictionaries, (b) their views in the value of dictionary for students, and (c) their inclusion of dictionaries in their classes. The questionnaire is divided into three parts. The first part includes 8 statements that are directed to investigate the general attitudes of EFL university teachers towards dictionaries. The second eight statements are administered to examine the teachers' opinions about how useful a dictionary is for students, whereas the third part investigates the actual use of the dictionaries in the classrooms.

The participants were asked to mark the statement that is more likely to represent their opinions about the importance of the dictionaries on the Likert scale that extends from "strongly agree", "agree", "not sure," "disagree" to "strongly disagree", and from "always", "often", "sometimes" "rarely" or "never". It also ranged from "excellent", "very good", and "quite good", "not sure" to "poor" in the part concerning the actual use of dictionaries in the classes. In many cases, the researchers asked the respondents to justify their answers orally and these justifications were recorded for future analysis.

\section{Analysis and Discussion}

This section is intended to provide an analysis of the data collected through the questionnaire. Each statement is examined individually as it is used to achieve a very specific function. A comment is used when some discrepancies are encountered where the researchers would expect a different response. For example, relatively similar to what 
was found by El-Sayed and Siddiek (2014), the first statement was shocking as we found that $42.5 \%$ of the respondents were not as enthusiastic as expected to integrate dictionaries as a part of effective teaching tool in their classes. The first part of the questionnaire is concerned with the general perceptions of dictionaries.

Table 1. Teachers' general attitudes towards dictionaries

\begin{tabular}{|c|c|c|c|c|c|c|c|}
\hline $\mathrm{NO}$ & Statement & $\begin{array}{l}\text { Strongly } \\
\text { agree }\end{array}$ & Agree & $\begin{array}{l}\text { Not } \\
\text { sure }\end{array}$ & Disagree & $\begin{array}{l}\text { Strongly } \\
\text { disagree }\end{array}$ & Total \\
\hline \multirow[t]{2}{*}{1} & \multirow{2}{*}{$\begin{array}{l}\text { Dictionaries are an integral part of } \\
\text { language learning. }\end{array}$} & 7 & 8 & 7 & 12 & 6 & 40 \\
\hline & & $17.5 \%$ & $20 \%$ & $17.5 \%$ & $30 \%$ & $15 \%$ & $100 \%$ \\
\hline \multirow[t]{2}{*}{2} & \multirow[t]{2}{*}{ Teachers should have dictionaries } & 13 & 15 & 5 & 7 & 0 & 40 \\
\hline & & $32.5 \%$ & $37.5 \%$ & $12.5 \%$ & $17.5 \%$ & $0 \%$ & $100 \%$ \\
\hline \multirow[t]{2}{*}{3} & \multirow{2}{*}{$\begin{array}{l}\text { Teachers need a dictionary more than } \\
\text { students }\end{array}$} & 3 & 4 & 1 & 24 & 8 & 40 \\
\hline & & $7.5 \%$ & $10.5 \%$ & $2.5 \%$ & $60 \%$ & $20 \%$ & $100 \%$ \\
\hline \multirow[t]{2}{*}{4} & \multirow{2}{*}{$\begin{array}{l}\text { Teachers should have a specialized } \\
\text { dictionary for particular aspects of } \\
\text { language (e.g. collocations). }\end{array}$} & 10 & 16 & 3 & 10 & 0 & 40 \\
\hline & & $25 \%$ & $40 \%$ & $10 \%$ & $25 \%$ & $0 \%$ & $100 \%$ \\
\hline \multirow[t]{2}{*}{5} & \multirow[t]{2}{*}{ Using the dictionary is pleasurable } & 2 & 3 & 6 & 21 & 8 & 40 \\
\hline & & $5 \%$ & $7.5 \%$ & $15 \%$ & $52.5 \%$ & $20 \%$ & $100 \%$ \\
\hline \multirow[t]{2}{*}{6} & \multirow{2}{*}{$\begin{array}{l}\text { Teachers should consult dictionaries } \\
\text { more than students }\end{array}$} & 15 & 11 & 8 & 4 & 2 & 40 \\
\hline & & $37.5 \%$ & $27.5 \%$ & $20 \%$ & $10 \%$ & $5 \%$ & $100 \%$ \\
\hline \multirow[t]{2}{*}{7} & \multirow{2}{*}{$\begin{array}{l}\text { Monolingual dictionaries rather than } \\
\text { the bilingual's are the normal choice } \\
\text { for teachers }\end{array}$} & 28 & 5 & 6 & 1 & 0 & 40 \\
\hline & & $70 \%$ & $12.5 \%$ & $15 \%$ & $2.5 \%$ & $0 \%$ & $100 \%$ \\
\hline \multirow[t]{2}{*}{8} & \multirow{2}{*}{$\begin{array}{l}\text { Electronic (online) dictionaries are } \\
\text { more useful than paper-based } \\
\text { dictionaries. }\end{array}$} & 19 & 13 & 3 & 3 & 2 & 40 \\
\hline & & $47.5 \%$ & $32.5 \%$ & $7.5 \%$ & $7.5 \%$ & $5 \%$ & $100 \%$ \\
\hline
\end{tabular}

As shown in Table 1 above, the first statement was intended to test whether university teachers agree or disagree with the idea of integrating dictionaries into the language learning/teaching process. The first statement carried both good and bad news: the bad news is that 12 teachers $(30 \%)$ disagree with the statement. It is bad because we expected a higher percentage to strongly agree with the statement. This could be justified as claimed by El-Sayed and Siddiek (2014: 174) that teachers consider dictionary skills "the sole responsibility of students and not an 'integral' part of a formal English language program" [emphasis in original]. However, the good news is that the total number of 15 participants agree with the statement, which may suggest that teachers started to appreciate the role of dictionaries in the learning process.

The second statement was used to test teacher's beliefs about possessing a dictionary, any kind of a dictionary. As expected, most participants (28: 70\%) agree that possessing a dictionary is needed maybe for emergency cases. The third statement is mainly used to test whether teachers believe that they need to consult dictionaries more than students. Our claim here is that teachers read more and may come across unfamiliar words, thus we assume that they would need to consult a dictionary more often. As clear from the table, most participants $(80 \%)$ disagree with the statement. Statement number 4 is an inquiry about specialized dictionaries; those concerned with collocations, idioms, phrasal verbs, and the like. The table shows that the participants do appreciate the need for such specialized dictionaries. Some of the teachers interviewed reported that they would consult an online dictionary for this kind of knowledge.

Statement number 5 was used to examine whether the teachers enjoy using the dictionary or not. Similar to what was found by El-Sayed and Siddiek (2014), the respondents did not enjoy using the dictionary as 29 (72.5) of them disagree with the statement. This could be attributed to the fact that dictionary users do benefit from it but do not enjoy it. As concerning the sixth statement, which was used to see if teachers need to consult a dictionary more often than their students, most participants, and $26(65 \%)$ agree with the statement. This was justified by some participants in the sense that teachers need to give true and accurate information to their students, so they need to refer to a dictionary to check before answering students' questions. Their answers were very close to statement number 3 . Statement 7 seeks to investigate the type of dictionary preferred by teachers; i.e. if the teachers prefer bilingual or monolingual dictionaries. As indicated in the table, 33 participants with a percentage of (82.5) agree that monolingual dictionaries are more appropriate for teachers than bilingual ones. The last statement claims that electronic dictionaries are more beneficial than paper-based dictionaries with which $32(80 \%)$ participants agree. This result was expected and in line with Chun (2004) who pointed out that "online and CD dictionaries provide user-friendly functions in searching and provide quick access to entry information".

To conclude this part of the section, we can assume that the responses were somehow reasonable, though sometimes there were some shocking answers. This could be either because the sample is relatively small, only 40 participants, or it could be the case that we, the researchers, were highly enthusiastic about the dictionary 
importance so we expected to receive answers similar to our expectations.

Table 2. Teachers' views on the value of dictionaries for students

\begin{tabular}{|c|c|c|c|c|c|c|c|}
\hline $\mathrm{NO}$ & Statement & $\begin{array}{l}\text { Strongly } \\
\text { agree }\end{array}$ & Agree & $\begin{array}{l}\text { Not } \\
\text { sure }\end{array}$ & Disagree & $\begin{array}{l}\text { Strongly } \\
\text { disagree }\end{array}$ & Total \\
\hline \multirow[t]{2}{*}{9} & \multirow{2}{*}{$\begin{array}{l}\text { University students can achieve } \\
\text { competence without resorting to } \\
\text { dictionaries }\end{array}$} & 12 & 10 & 3 & 13 & 2 & 40 \\
\hline & & $30 \%$ & $25 \%$ & $7.5 \%$ & $32.5 \%$ & $5 \%$ & $100 \%$ \\
\hline \multirow[t]{2}{*}{10} & \multirow{2}{*}{$\begin{array}{l}\text { Students should consult dictionaries } \\
\text { constantly. }\end{array}$} & 9 & 12 & 2 & 12 & 5 & 40 \\
\hline & & $22.5 \%$ & $30 \%$ & $5 \%$ & $30 \%$ & $12.5 \%$ & $100 \%$ \\
\hline \multirow[t]{2}{*}{11} & \multirow{2}{*}{$\begin{array}{l}\text { Less competent students are more } \\
\text { likely to consult dictionaries }\end{array}$} & 27 & 3 & 7 & 2 & 1 & 40 \\
\hline & & $67.5 \%$ & $7.5 \%$ & $17.5 \%$ & $5 \%$ & $2.5 \%$ & $100 \%$ \\
\hline \multirow[t]{2}{*}{12} & \multirow{2}{*}{$\begin{array}{l}\text { Using dictionaries will undoubtedly } \\
\text { increase students' vocabulary. }\end{array}$} & 11 & 15 & 9 & 3 & 2 & 40 \\
\hline & & $27.5 \%$ & $37.5 \%$ & $22.5 \%$ & $7.5 \%$ & $5 \%$ & $100 \%$ \\
\hline \multirow[t]{2}{*}{13} & \multirow{2}{*}{$\begin{array}{l}\text { Some of the students' pronunciation } \\
\text { vocabulary are at least caused by a } \\
\text { lack of dictionary use. }\end{array}$} & 1 & 8 & 11 & 17 & 3 & 40 \\
\hline & & $2.5 \%$ & $20 \%$ & $17.5 \%$ & $42.5 \%$ & $7.5 \%$ & $100 \%$ \\
\hline \multirow[t]{2}{*}{14} & \multirow{2}{*}{$\begin{array}{l}\text { One way of improving students' } \\
\text { writing is by urging them to use } \\
\text { dictionaries more. }\end{array}$} & 2 & 2 & 25 & 8 & 3 & 40 \\
\hline & & $5 \%$ & $5 \%$ & $62.5 \%$ & $20 \%$ & $7.5 \%$ & $100 \%$ \\
\hline \multirow[t]{2}{*}{15} & \multirow{2}{*}{$\begin{array}{l}\text { Dictionary skills can be an indicator of } \\
\text { a student's linguistic competence. }\end{array}$} & 1 & 3 & 5 & 22 & 9 & 40 \\
\hline & & $2.5 \%$ & $7.5 \%$ & $12.5 \%$ & $55 \%$ & $22.5 \%$ & $100 \%$ \\
\hline
\end{tabular}

The second part of the questionnaire aims at investigating the teachers' views about the values of dictionaries to students; i.e. if the use of dictionaries has a positive impact on the students' achievements in different language skills. Statement 9 tests teachers' opinions about the students' ability to achieve competence in English without consulting a dictionary. The table shows that $22(55 \%)$ of the respondents agree that students can achieve and do well without consulting a dictionary. This could be attributed to the fact that some teachers have in mind the image of a traditional dictionary and that when they read the statement an image of a student looking up words in a dictionary come to their minds, neglecting the fact that online dictionaries with various and new forms that are different from the traditional dictionary are available for users of all types.

Statement 10 concerns the regular use of a dictionary. The respondents almost split between agreeing and disagreeing with $21(52.5 \%)$ agreeing that students need to consult a dictionary regularly. The skeptic nature of the answers may indicate that one of the following two options: the first is that teachers know that there are other resources available for students to learn new vocabulary like chatting with native speakers, for instance. Or it could be the case that teachers themselves are not aware of the components of a good dictionary. Statement 11 seeks to find the relationship between competence and consultation habits for the teachers. The table shows that most teachers, $30(75 \%)$, correlate less competency with a high frequency of using a dictionary; i.e. the less competent the student the more frequently he/she uses the dictionary.

As the questionnaires proceed, the questions were more directed to specific skills. In line with the previous statement, statement 12 indicates that as students consult their dictionaries they will have a larger English repertoire with a total number of $26(65 \%)$ respondents agreeing with the statement. That is why they agree with the statement 11; assuming that less competent students need the dictionary to develop their linguistic vocabulary.

In the statement 13 , respondents were more likely to be convinced that dictionary use does not students to improve their pronunciation skills. Only $9(22.5 \%)$ of the participants agree that there is a deeply rooted relationship between pronunciation and dictionaries. This could be justified in the sense that students, and teachers as well, are highly dependent on phonetics and phonology textbooks, where a large number of examples are provided to explain a certain sound or a certain phonological process, neglecting the essential role a dictionary can play. In this respect, we recommend that teachers should ask their students to check their dictionaries for more and more examples. This way, students will indirectly find the core relationship between pronunciation and dictionary.

Again, statement 14 was utilized to test whether the English teachers see any relationship between using a dictionary and improving the writing skills. Most participants, 25 (62.5\%), were not sure while $11(27.5 \%)$ disagree. This means that they did not see a relation between writing skills and dictionaries. The final statement in this part of the questionnaire, 15 , is used to examine the claim that if students have an excellent dictionary using skills, they will achieve better results, and thus, dictionary consultation skills may indicate linguistic competence. As expected, $31(72.5 \%)$ of the participants disagree with the statement. A relatively similar finding was found by El-Sayed and Siddiek (2014). 
Table 3. How teachers make use of dictionaries in classroom activities

\begin{tabular}{|c|c|c|c|c|c|c|c|}
\hline NO & Statement & Always & Often & Sometimes & Rarely & Never & Total \\
\hline \multirow[t]{2}{*}{16} & \multirow{2}{*}{$\begin{array}{l}\text { I encourage my students to use online } \\
\text { dictionaries during classes }\end{array}$} & 0 & 1 & 2 & 13 & 24 & 40 \\
\hline & & $0 \%$ & $2.5 \%$ & $5 \%$ & $32.5 \%$ & $60 \%$ & $100 \%$ \\
\hline \multirow[t]{2}{*}{17} & \multirow{2}{*}{$\begin{array}{l}\text { I observe the rate of my students who use } \\
\text { dictionaries during lectures. }\end{array}$} & 0 & 2 & 4 & 5 & 29 & 40 \\
\hline & & $0 \%$ & $5 \%$ & $10 \%$ & $12.5 \%$ & $72.5 \%$ & $100 \%$ \\
\hline \multirow[t]{2}{*}{18} & \multirow{2}{*}{$\begin{array}{l}\text { I tell my students that good use of } \\
\text { dictionaries can have a positive impact on } \\
\text { their language performance }\end{array}$} & 0 & 4 & 9 & 8 & 19 & 40 \\
\hline & & $0 \%$ & $10 \%$ & $22.5 \%$ & $20 \%$ & $47.5 \%$ & $100 \%$ \\
\hline \multirow[t]{2}{*}{19} & \multirow{2}{*}{$\begin{array}{l}\text { I train my students in dictionary related- } \\
\text { exercises (e.g. pronunciation, parts of } \\
\text { speech, collocations.) }\end{array}$} & 1 & 14 & 8 & 11 & 6 & 40 \\
\hline & & $2.5 \%$ & $35 \%$ & $20 \%$ & $27.5 \%$ & $15 \%$ & $100 \%$ \\
\hline \multirow[t]{2}{*}{20} & \multirow{2}{*}{$\begin{array}{l}\text { I point out to my students the relative } \\
\text { advantages and disadvantages of using } \\
\text { monolingual and bilingual dictionaries. }\end{array}$} & 2 & 2 & 6 & 13 & 17 & 40 \\
\hline & & $5 \%$ & $5 \%$ & $15 \%$ & $32.5 \%$ & $42.5 \%$ & $100 \%$ \\
\hline \multirow[t]{2}{*}{21} & \multirow{2}{*}{$\begin{array}{l}\text { I integrate dictionary skills into my general } \\
\text { English syllabus. }\end{array}$} & 0 & 0 & 2 & 23 & 15 & 40 \\
\hline & & $0 \%$ & $0 \%$ & $5 \%$ & $57.5 \%$ & $37.5 \%$ & $100 \%$ \\
\hline \multirow[t]{2}{*}{22} & \multirow{2}{*}{$\begin{array}{l}\text { I direct my students to muse dictionaries } \\
\text { independently at home as part of their } \\
\text { general language learning technique. }\end{array}$} & 4 & 9 & 11 & 4 & 12 & 40 \\
\hline & & $10 \%$ & $22.5 \%$ & $27.5 \%$ & $10 \%$ & $30 \%$ & $100 \%$ \\
\hline
\end{tabular}

In table 3, we were concerned with the applications of teachers' dictionary use in their English classrooms. Again, we were highly enthusiastic and were expecting that English teachers would, at least, advise the students to consult their dictionaries very often. However, the teachers' responses showed opposite to our expectations. For example, Statement 16 is concerned with the teachers' encouragement for using dictionaries in the English classrooms. As shown in the table, none of the teachers simply asks their students to do so, while $24(60 \%)$ never do. Some of the teachers who were interviewed claimed that students may use the internet for different things other than the intended task, so they cannot allow students to use their mobiles in the classroom. For those who sometimes (32.5\%) allow their students to use dictionaries in the classroom, MA students are only allowed to dos so. Statement 17 was similar to the previous one with a relatively higher percentage $(72.5 \%)$ who never observe the rate of their students who use dictionaries. This could be explained in the sense that even though teachers are somehow aware of the importance of dictionaries they do not allow students to use it in the classroom because it may interrupt the classes.

In statement 18, almost half of the participants (47.5\%) never tell directly tell their students how important the dictionary is. Again, this should not be seen as contradictory with the importance of the dictionary, rather it can be seen as teachers' opinions that students should go into universities with all the needed equipment, including dictionary skills. Statement 19 was relatively better with $(35 \%)$ of the respondents often train students how to use the dictionary as it is related to the exercises in the textbooks if there is any. This may indicate the teachers' as well as their students' overreliance on the textbooks as the only source of knowledge for university students. This is in line with El-Sayed and Siddiek (2014: 176) who maintained that teachers would normally train their students on dictionary-related exercises if the textbooks contain such lexicographical components. Although teachers themselves prefer monolingual dictionaries, most of them never $(42.5 \%)$ or rarely $(32.5 \%)$ explicitly explain the advantages or even disadvantages of the monolingual or bilingual dictionaries as clear from statement 20 . Statement 21 indicates that most of the teachers rarely $(57.5 \%)$ while $(37.5 \%)$ never integrate dictionary using skills in their course syllabus. Again, this seems to originate from the fact that teachers do consider using or consulting a dictionary a personal responsibility on the part of the students, or that students should come to universities ready and familiar with such "basic skills", we would say. This is confirmed with the relatively higher percentages of the teachers who direct their students to use dictionaries on their own at home as clear in statement 22 above.

To conclude this part of the section, we, the researchers, may claim that deeply in the minds of university teachers is the idea that university students come to university equipped with the dictionary using skills. Therefore, most of them never ask their student to consult a dictionary in the classroom. Rather, directions were made to students to consult their dictionaries when necessary and mainly at home, not in the classes.

\section{Conclusion}

Because we were highly motivated and highly optimistic, we expected that EFL university teachers would at least pass their positive views about dictionaries to the new generations of learners. We are sorry to say that after analyzing the data we were depressed. The findings revealed that although teachers do believe that dictionaries are of great importance as indicated from their responses to the first part of the questionnaire, they thought that it is 
only needed when there is a need or when it is included in textbooks and course syllabi. Based on the findings, we may claim that the only way to make students and teachers use dictionaries regularly is through integrating dictionaries in the textbooks and course syllabi. We also claim that by incorporating dictionary usage into classroom practice regularly, EFL teachers will raise their students' awareness of the specific type of information they can find in the dictionary, how they can use it to serve academic purposes, and become more autonomous learners.

\section{Recommendations for further research}

The sample of the study is relatively small - 40 participants - and thus, the results cannot be generalized. For further investigation, we recommend that a larger sample of participants should be used to achieve more reliable results. Besides, school teachers may be included in the sample to have a more comprehensive understanding of the image of the dictionary and the dictionary skills needed by users and EFL learners. Gender can be also investigated about dictionary attitudes and classroom practices.

\section{References}

Adamska-Salaciak, A. and Ilan K. 2016. 'Introduction: Toward Better Dictionary for Learners.' International Journal of Lexicography 29. 3: 271-278.

Al-Ajmi, H. 2008. 'The Effectiveness of Dictionary Examples in Decoding: The Case of Kuwaiti Learners of English.' Lexikos 18: 15-26.

Alhaisoni, E. 2016. EFL Teachers' and Students' Perceptions of Dictionary Use and Preferences. International Journal of Linguistics 8.6: 31-52.

Al-Homoud, F. 2017. Dictionary use by Saudi EFL University Preparatory Program Students. International Journal of Linguistics 9.4: 15-27.

Ayoub, M., Khalid M., and Abdul Ghafoor A. 2017. A Study of Dictionary Using Habits of Students at Secondary Level in the Urdu Medium Schools in District Khanewal-Pakistan. Global Journal of Management, Social Sciences and Humanities 3.3: 515-535.

Benzehra, R. 2012. Issues and Challenges for a Modern English-Arabic Dictionary. Dictionaries: Journal of the Dictionary Society of North America 33: 83-102.

Bogaards, P. 2005. Dictionaries and Productive Tasks in a Foreign Language. Kernerman Dictionary News 13 : $20-23$.

Chun, V. 2004. EFL Learners' Use of Print and Online dictionaries in L1 and L2 writing processes. MultimediaAssisted Language Learning 7.1: 9-35.

El-Sayed, N. and A. Siddiek. 2014. Exploring the English Language Teachers' Attitudes towards the Use of Pedagogical Dictionaries in Their Classes (Sudanese Perspective). International Journal of Applied Linguistics \& English Literature 3.3: 171-187.

Gilles-Maurice de S. and D. J. Prinsloo. 2011. Do Dictionaries Define on the Level of Their Target Users? A Case Study for Three Dutch Dictionaries. International Journal of Lexicography 24.1: 5-28.

Hamouda, Arafat. 2013. A Study of Dictionary Use by Saudi EFL Students at Qassim University. Study in English Language Teaching 1.1: 227-257.

Hartmann, K. 1983. The Bilingual Learner's Dictionary and its Uses. Multilingua 2.4:195-201.

Hartmann, K. 1992. Lexicography, with Particular Reference to English Learners' Dictionaries. Language Teaching 25.3: $151-159$.

Ilson, R. 1985. Dictionaries, Lexicography and Language Learning. Pergamon Press: Oxford.

Kim, S. 2017. EFL Learners' Dictionary Consultation Behaviour During the Revision Process to Correct Collocation Errors. International Journal of Lexicography 30: 1-15.

Lew, R. 2016. Can a Dictionary Help You Write Better? A User Study of an Active Bilingual Dictionary for Polish Learners of English. International Journal of Lexicography 29.3: 353-366.

Liang, P. and Dan X. 2015. The Contribution of Dictionary Use to the Production and Retention of the Middle Construction for Chinese EFL Learners. International Journal of Lexicography 30.1: 85-107.

Metruk, R. 2017. The Use of Electronic Dictionaries for Pronunciation Practice by University Students. Teaching English with Technology 17.4: 38-51.

Nesi, H. 1999. A User's Guide to Electronic Dictionaries for Language Learners. International Journal of Lexicography 12.1: 55-66.

Nesi, H. (2002). A Study of Dictionary Use by International Students at a British University. International Journal of Lexicography 15.4: 277- 305

Pius ten Hacken. (2009). What is a Dictionary? A View from Chomskyan Linguistics. International Journal of Lexicography 22.4: 399-421.

Tarp, S. (2002). Basic Problems of Learner's Lexicography. Lexikos 14: 222-252.

Tarp, S. and Rufus H. Gouws. 2012. School Dictionaries for First-Language Learners. Lexikos 22: 333-351. 
Weschler, R., \& Pitts, C. 2000. An Experiment Using Electronic Dictionaries with EFL Students. Accessed on 19 November 2018. http://iteslj.org/Articles/Weschler ElectroDict.html 